\title{
Flash flood risk assessment for upper Teesta river basin: using the hydrological modeling system (HEC-HMS) software
}

\author{
Subhra Prakash Mandal ${ }^{1}$ Abhisek Chakrabarty ${ }^{1}$
}

Received: 15 March 2016/ Accepted: 16 March 2016/Published online: 29 March 2016

(C) Springer International Publishing Switzerland 2016

\begin{abstract}
Flash flood is one of the devastating natural disaster in the mountainous region of India. In SikkimDarjeeling Himalaya Teesta Watershed is a probable flash flood occurrence zone. The present study is an attempt to develop a simulation model of surface runoff in upper Teesta basin, which directly related to catastrophic flood happenings. At the first stage, a primary unit hydrograph is developed with time for an excess rainfall event by estimating the stream flow response at the outlet of the watershed. Specifically, the methodology was based on meteorological and morphological data processing in the geospatial environment and on data editing. Rainfall timeseries data collected from India Meteorological Department and processed to calculate water flow to evaluate peak Discharge over time and estimate the runoff volume. Apart from the meteorological data, background data such as topography, drainage network, land cover and geological data were also collected. Clipping off the watershed from the entire area and the streamline generation for Teesta watershed was done from Aster DEM data using the LPS Tool and Arc GIS environment. A part of this model is to build geospatially input $\mathrm{CN}$ grid data based on land use, hydrological soil group and eluviation of the area. The analysis of the different hydraulic model to detect flash flood probability was done using HECRAS, and HEC-HMS Software, which was of great
\end{abstract}

Subhra Prakash Mandal

subhra.rs.destiny@gmail.com;

subhra.rs.gis@mail.vidyasagar.ac.in

Abhisek Chakrabarty

abhisek@mail.vidyasagar.ac.in

1 Department of Remote Sensing and GIS, Vidyasagar University, Midnapore, W.B., India importance to achieve the final result. $313 \mathrm{~km}^{2}$ area was found to be most vulnerable to flash flood includes Singtam, Melli, Jourthang, Chungthang and Lachung and $655 \mathrm{~km}^{2}$ as moderately susceptible includes Teesta Bazar, Rangpo, Yumthang, Dambung and Thangu Valley. The simulation model based on the watershed and its surface characteristics of the soil, land use land cover and altitude of the area and the discharge volume of water with time. This model validated by inserting the rainfall data of a flood event, which took place on 2nd to 5th October in 1968 , and $78 \%$ of the actual area flooded reflected in the output of the model.

Keywords Flash flood - Simulation model $\cdot$ Hydrograph . CN grid · Pick discharge

\section{Introduction}

The coincidence of flash flood and debris flows is a particular concern because it may amplify hazard corresponding to the individual generative process taken in isolation (Borga et al. 2014). The recent flood in the Mandakini River in Kedarnath (14-17th June, 2013) is a classic example of flash floods that devasted Uttarakhand by killing thousand of people (Das et al. 2015). The disaster was integrated effect of high intensity rainfall, sudden breach of Chorabari Lake and very steep topography (Rao et al. 2014). The Origin of Teesta river is The Pahunri Glacier, and it flows southward through gorges and rapid flow in the Sikkim Himalaya. In Past, the Teesta used to flow beside Rangpo town, where the Rangpo River also meets, and forms the border between Sikkim and West Bengal up to Teesta Bazaar. Just before the 
Teesta Bridge, in the junction point of the road to Kalimpong and Darjeeling, the river is linked by its major tributary, the Rangeet River. At this point, it changes the flow to southwards and flowing into West Bengal. The river hits the plains at Sevoke. The river then flows its way to Jalpaiguri and then to Rangpur District of Bangladesh, finally merged with the Brahmaputra River at Fulchori. The Teesta is characterized by a complex hydrological regime. The river is fed not only by precipitation, but also by melting glaciers and snow as well as ground water (Wiejaczka et al. 2014).

It is a hilly region, the relief rainfall or the orographic rains are very common and in the upper part, the icecaps are also present and ice melt water also added in the stream. If any flash flood occurs, losses of life and property and various other problems are inevitable. In 1968, this kind of flash flood occurred here. Therefore in future, there are also ample chances of occurrence of this kind of hazard in Teesta river basin. The rainfall distribution in the hilly region of the river system by using the travel time coordinate is the significant property of spatial rainfall variability when considering flood response modeling. (Zoccatelli et al. 2010).

\section{Objective of the study}

The primary purpose is (1) to construct a unit of hydrograph for an excess rainfall event by estimating the stream flow response at the outlet of each sub-watershed and simulation of the extent of inundation of the river banks. (2) Extraction of drainage line and their catchment from DEM and delineation of watershed and sub-watersheds. (3) Estimation of Runoff from NRCS Curve Number which is a function of land use land cover and hydrologic soil group of the area. (4) Generation of hydrograph, peak discharge time and peak discharge volume based on excess rainfall event.

\section{Study area}

The study area is the upper Teesta river basin covering the whole Sikkim and part of the Darjeeling District of West Bengal. The study area situated between Longitude $80^{\circ} 00^{\prime} \mathrm{E}-88^{\circ} 55^{\prime} \mathrm{E}$ and Latitude $26^{\circ} 55^{\prime} \mathrm{N}-28^{\circ} 08^{\prime} \mathrm{N}$ which shows in Fig. 1.

The Teesta River is a right bank tributary of the Brahmaputra, draining approximately $8600 \mathrm{~km}^{2}$ of Sikkim Darjeeling Himalaya. It's origin in the Pauhunri massif $(7127 \mathrm{~m})$, and the total length of the mountain section of the river amounts to $182 \mathrm{~km}$ (Wiejaczka et al. 2014).

\section{Materials and methods}

\section{Data source}

Landsat 7 ETM+ data with 30-m spatial resolution, Aster DEM with 30-m resolution, Rainfall data of India Metrological Department, Soil type map are uses as the data. The information of the data shows in Table 1.

\section{Watershed and stream line delineation}

Steepness represents unique morphological features of flash flood catchments. Relief is important since it may affect flash flood occurrence in particular catchments by a combination of two main mechanisms there are orographic effects augmenting precipitation and anchoring convection, and topographic relief promoting the rapid concentration of stream flow (Marchi et al. 2010). The Teesta basin covers a significant area; the software Arc GIS 10.1 has used for automatic watershed demarcation. To run this process, a corrected Digital Elevation Model of this area is used. An Aster GDEM has used for this purpose. The interpolation method is used to correct it manually. The run and fill tool is used to fill the depressions in ArcGIS environment. The image is call fill image. The flow direction image has been generated from the fill image. Then from the flow direction image, flow accumulation image has been created. This flow accumulation model represents the flow path of the river channel in a raster mode image. Then using this condition, the Streamline have extracted from the flow accumulation image. From the stream image based on the stream order, stream linked image have been generated. It divides the stream grid into segments. Stream links are the sections of a stream that connect two successive junctions and an outlet point. The basis of the outlet point of the Stream link image, the whole basin has divided into various sub-basins. The stream generates its particular catchment area, and each outlet point creates minimum two small streams. By this process of vectorizing, there produced 377 polygons, and each stream created a polyline. After that, the adjoining catchment area has been attached to outlet points. The adjacent basins made from the flow, are not the tributary of this river. The accumulation points have been located and based on the accumulation point the area of the project have been demarcated.

\section{Sub-basin division}

Runoff coefficient is an important diagnostic variable of runoff generation and catchment response. To compare catchments at different time scales to understand the 
Fig. 1 Location map of the study area

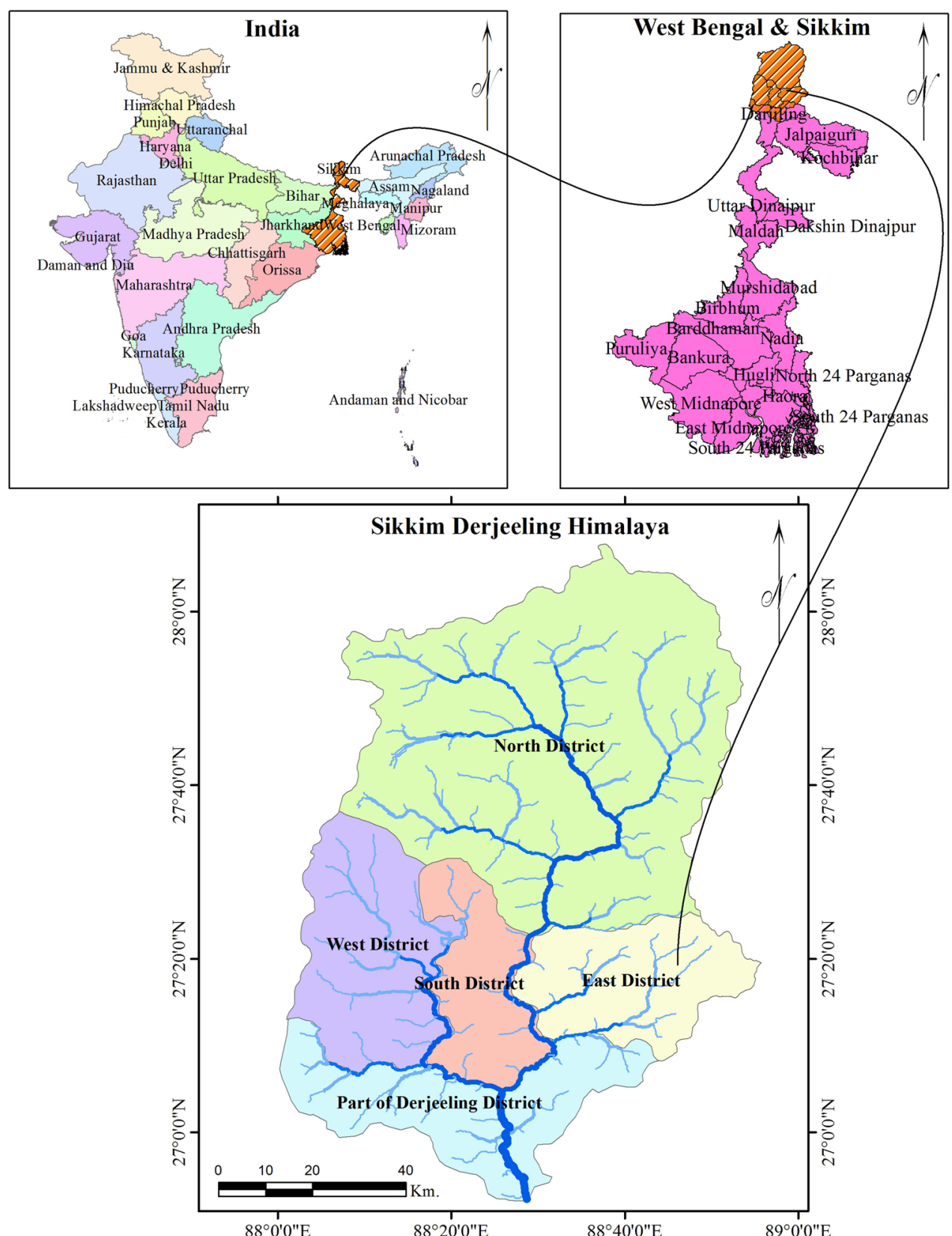

Table 1 Satellite images and other data sources

\begin{tabular}{llll}
\hline Name & Spatial resolution & Date & Source \\
\hline Landsat 7 ETM+ & $30 \mathrm{~m}$ & 6.12 .2014 & USGS global visualization viewer \\
Aster DEM & $30 \mathrm{~m}$ & 15.03 .11 & http://gdem.ersdac.jspacesystems.or.jp \\
Rainfall data & & $02.10 .1968-05.10 .1968$ & India Metrological Department, Alipur, Kolkata \\
Soil map & West Bengal & & N.B.S.S and L.U.P \\
& Sikkim & & Natural resources atlas of Sikkim \\
\hline
\end{tabular}

dampening effect on rainfall of various landscapes (Garambois et al. 2014). Based on the stream and outlet point total 377 numbers of the basin have been generated.
These massive numbers of basins are too large for the analysis. Therefore, basins have been merged and created 17 number of sub-basin. 

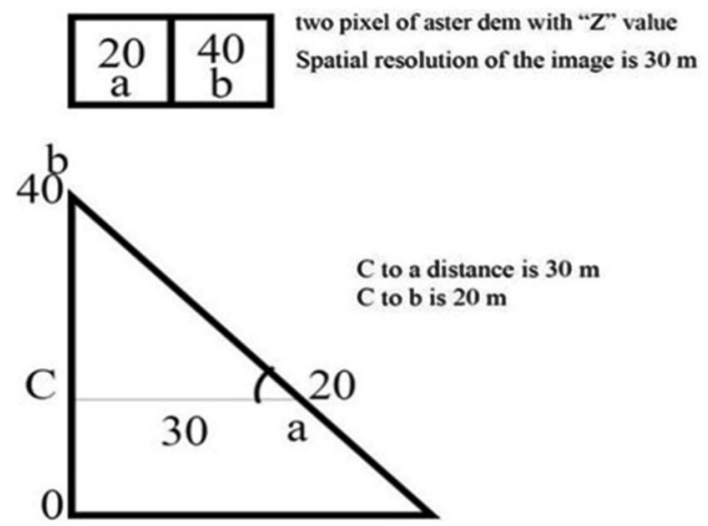

Here the slope is the value of angel " a"

Fig. 2 Slope calculation diagram

\section{Basin characteristics}

To calculate the hydrograph, the characteristic of basins is one of the significant factors, which Connect River of each stream segments. The spatial rainfall variability plays a major role when rainfall fields are systematically structured across locations with equal flow distance coordinates (Wu et al. 2015), as it occurs in the case of orographic effect and when catchments are elongated in the direction perpendicular to the mountainous range (Sangati et al. 2009). The slope is another factor, which calculated From the DEM every pixel represents the $Z$ value of the area. Figure 2 shows the distance between ' $a$ ' to ' $C$ ' is $30 \mathrm{~m}$ and ' $C$ ' to ' $b$ ' is $20 \mathrm{~m}$. The slope has calculated using the following formula.

$\tan a=\frac{20}{30} \quad \therefore \quad a=\tan ^{-1} \times \frac{20}{30}=33^{\circ} 41^{\prime} 24.24^{\prime \prime}$

For multiple elements of simulation, results from global and element summary tables include information on peak flow, the total volume of water, and other variables of timeseries table and graph are available for simulation runs (Koutroulis and Tsanis 2010). The spatial resolution if know of DEM then slopes has been computing quickly. Using this slope map the river slope and basin slope has generated.

\section{Basin longest flow path}

Generation is another feature of this work. Here based on the individual sub-basins the longest flow path has been calculating from the vector river layer by using HEC-HMS software environment.

\section{Basin centroid}

It is for identification of the centroid of each sub-basin. This centroids are located at the center of gravity of each

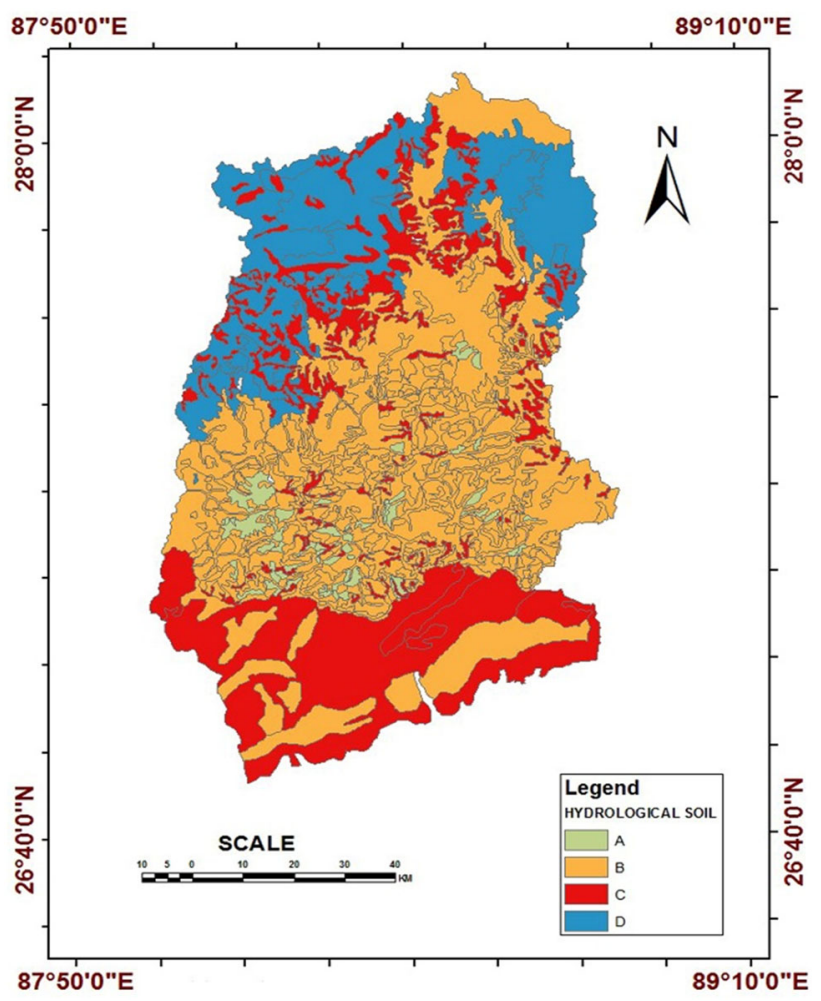

Fig. 3 NRCS hydrological soil group

sub-basin. Therefore, it is one of the useful parameters of hydrograph generation. After generating the centroids, the centroid elevation has been computed from the Aster DEM.

\section{Hydrological soil division}

The calculation of the $\mathrm{CN}$ number, need to classify the soil of the area by the runoff capability. Those groups of classification are well-known as hydrological soil group. The runoff properties classify the soils. Soil Group 'A' has low runoff potential and high infiltration rates. This soil is well to excessively drained and has a high rate of water transmission into the ground. This type of soil can infiltrate greater than 0.30 -inch water per hour. Soil Group 'B' has low to moderate runoff. It consists well to reduced drainage, so it has a high rate of water transmission moderately into the ground. This type of soil can infiltrate $0.15-0.30$-inch water per hour. Soil Group 'C' have flat infiltration rate, so the runoff is quite higher. Its transmission rate is $0.05-0.15$-inch water per hour. Soils Group ' $\mathrm{D}$ ' has high runoff potential and very low infiltration rate. These soils have a permanent high water table, so the infiltration rate is subtle like $0.0-0.05$ inch per hour. The following Fig. 3 shows the division of soil group. 


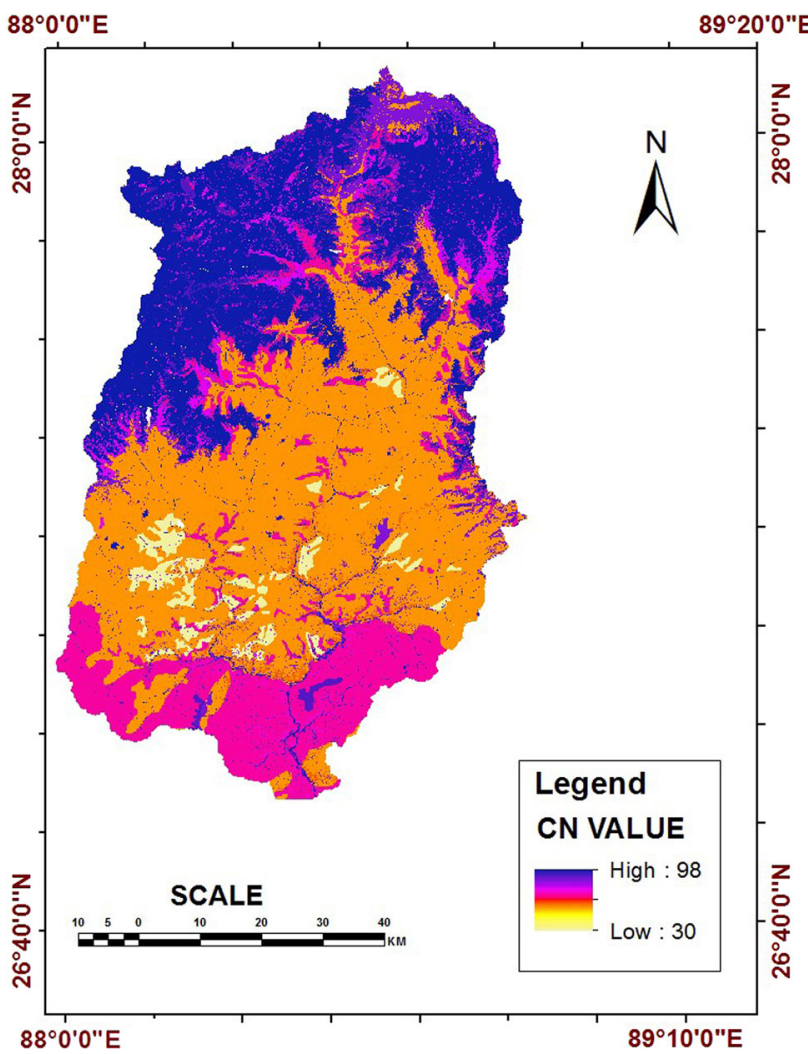

Fig. 4 NRCS curve number grid image

\section{Land use land cover of the study area}

Land use land cover is a very imperative aspect for the curve number calculation. Based on the land use and land cover the curve number changes, because the different land cover and land use have a different type of runoff capacity. Based on the hydrological soil group and land uses it converted to vector format for the soil land use, and the Union process has been run to generate soil land use polygons. For this study area, total 551,860 numbers of polygons have been created. Those polygons are attributed based on the curve number of SCS process. SQL Quarries in Arc GIS are used for this enormous number of data input.

\section{CN grid generation}

In Fig. 4 shows the $\mathrm{CN}$ value of each pixel based on the land use and hydrological soil group. The behavior of the $\mathrm{CN}$-rainfall function produced by the simplified two $\mathrm{CN}$ system approached theoretically; it analyzed scientifically, and it is found to be related to the variation observed in the natural watershed (Soulis and Valiantzas 2012). The model runs based on this $\mathrm{CN}$-grid. In Arc-GIS environment, the HMS model SI unit system has been used. Based on the $\mathrm{CN}$ grid image, characteristics of the watershed and the drainage pattern, the sub-watershed have been divided, and their all other attributes have been filed in their center of gravity or centroid. Finally, the model has been generated and exported to HMS environment.

\section{Hydrologic modeling system}

The hydrologic modeling system (HEC-HMS) intended to simulate the complete hydrologic processes of dendrite watershed systems. The HMS software comprises several traditional hydrologic analysis procedures such as event infiltration, unit hydrographs, and hydrologic routing. It also includes procedures necessary for continuous simulation including evapotranspiration, snowmelt, and soil moisture accounting (US Army Corps of Engineers Hydrologic Engineering Centre (USACE) 2008). Advanced capabilities also provided for gridded runoff simulation using the linear quasi-distributed runoff transform. Supplemental analysis tools provided for parameter estimation, depth-area analysis, flow forecasting, erosion and sediment transport, and nutrient water quality from the above flow diagram Fig. 5.

The software features a completely integrated work environment including a database, data entry utilities, computation engine, and results reporting tools. A graphical user interface allows the seamless user movement between the different parts of the software. Simulation results are stored in HEC-DSS (data storage system) and can be used in conjunction with other software for studies of water availability, urban drainage, flow forecasting, future urbanization impact, reservoir spillway design, flood damage reduction, floodplain regulation, and systems operation (US Army Corps of Engineers Hydrologic Engineering Centre (USACE) 2008).

\section{Hydrologic simulation}

Mechanism conditions control the flow time of the river water. Mechanism conditions contain a starting date and time, ending date and time, and a time interval (Borga et al. 2011). A simulation created by linking a basin model, meteorological model, and mechanism conditions. Route selections comprise a precipitation or flow ratio, ability to apart from all basin state information at a point in time, and able to initiate a simulation run (Zenon et al. 2010). The simulation experiment showed that the transition from arid to close to initial saturation conditions may result in a relative increase of more than $100 \%$ of both peak discharge and runoff volume (Nikolopoulos et al. 2011). For multiple elements of simulation results from global and element summary tables include information on peak flow, the total volume of water, and other variables of time-series table and graph are input the Fig. 6 for simulation runs. 
Fig. 5 Flow chart of model generation

Fig. 6 Flow chart of flood simulation
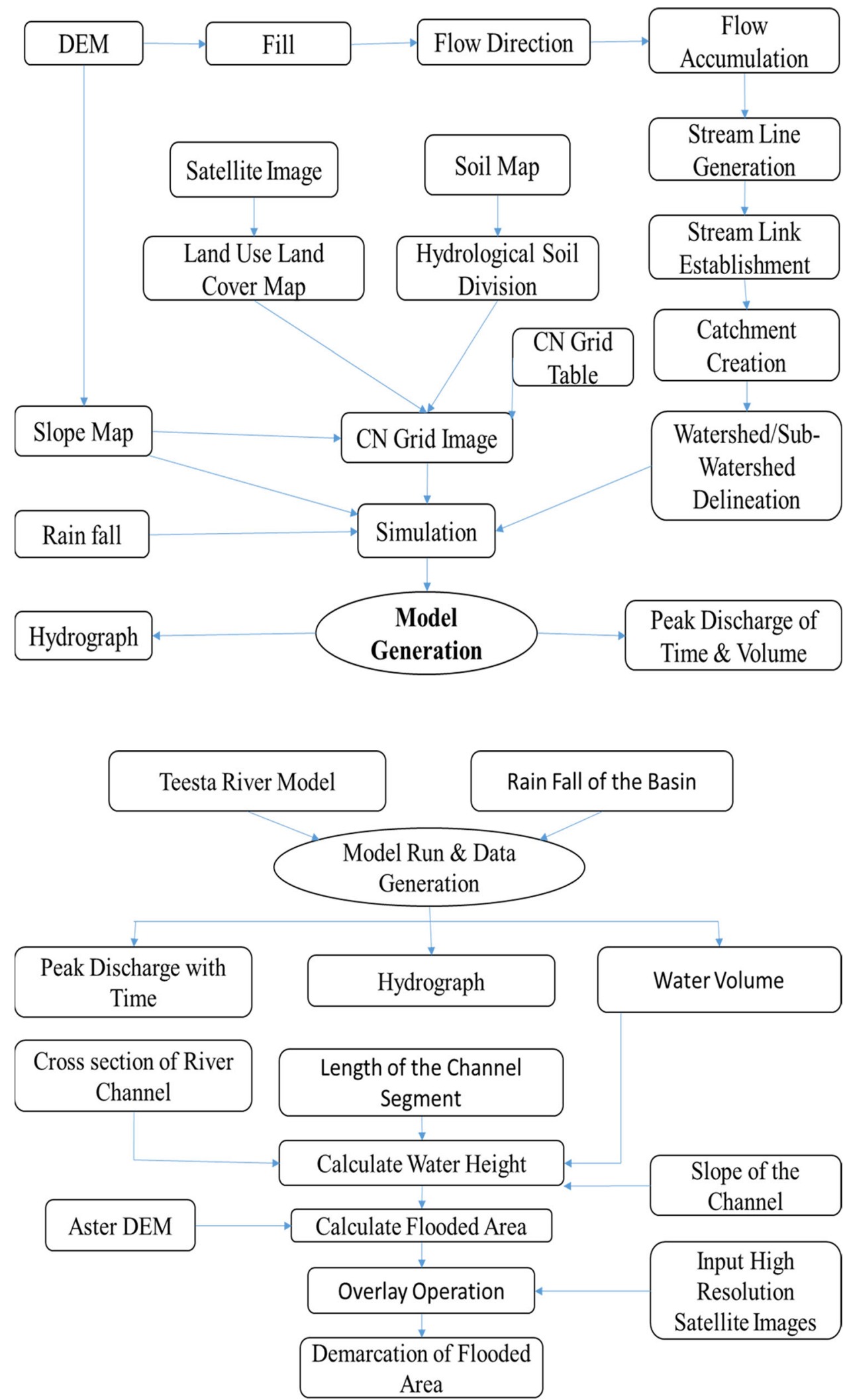
Fig. 7 The Teesta river simulation model

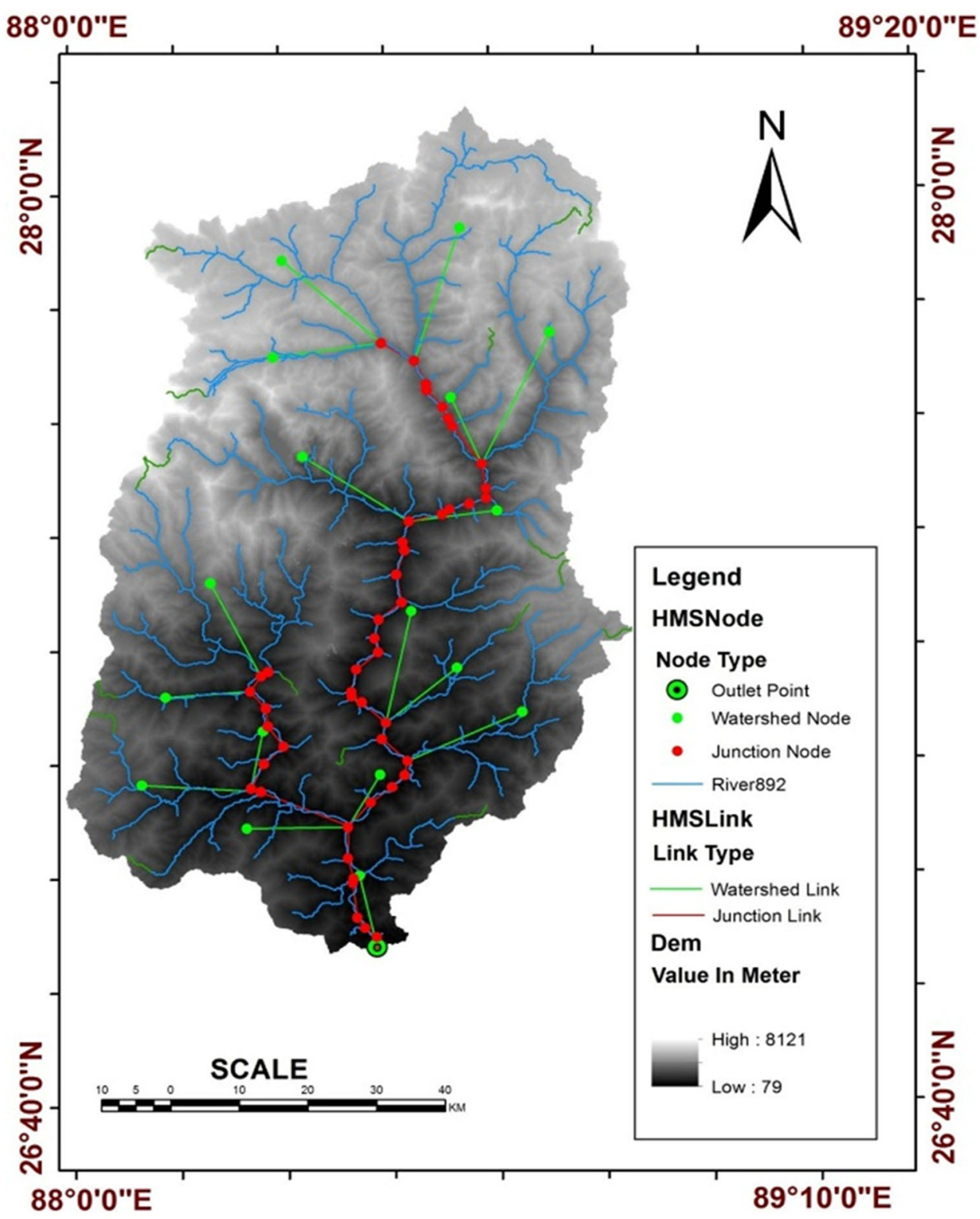

\section{Result and discussion}

The Teesta River model has been run based on rainfall and observed data that can generate an effect of water flow at each junction point of the river. From this model the hydrograph, peak discharge water volume, speed and peak discharge time has been generated.

\section{Model information}

In this model the green points represent the Sub-watershed centroid, means this is the center of gravity of each subbasin. In this model, all junction point data of each subbasin has been put. The data are like that, the area of that sub-basin, the average slope of the sub-basin, number of rivers present in that sub-basin, average $\mathrm{CN}$ value of that sub-basin, the amount of rainfall occur in that sub-basin and the period of the rainfall. Based on this data the model runs and generates the result about that sub-basin. In Fig. 7, red points represent the junction point of the sub-basin and the river. At that point, some information about the intersection has been entered. That are like, the mainstream, the upstream and the downstream. Watershed node helps to calculate the water volume link between the sub-watershed and the line that has pointed junction point. That link supports to calculate the flow of water. In this connection, the data like the slope of the river of any segment, river routing pattern, time is taken for water flow from starting point to the end of a section are also included in the link of Fig. 7. 


\section{Result from the model}

Various types of information can be generate using this model, based on the rainfall amount of some days. That information is peak discharge of water volume, time of peak discharge at any point, water speed at the time of peak discharge. This information is useful for flood analysis. From the result of pick discharge time and amount of water, the water volume is calculated which is very useful for flash flood study.

\section{Hydrograph generation}

In this model, the rainfall data with 6-h interval has been imported. Based on the rainfall amount within a time span and loss of the moisture, hydrograph has been computed and plotted. Thus, hydrograph at each point of the river channel has been calculated and plotted on the chart.

\section{Discharge calculation}

Based on Table 2 the rainfall, Loss of the precipitation, river channel slope and another characteristics, the discharge of a river channel has been computed. Whole river area has been analyzed by this process to calculate the discharge.

\section{Application of the model}

To understand the workability of the model, some particular points have been selected. To apply the model and generate the outcome based on the field visit, observation and knowledge of some criteria like the orientation of the settlement nearer to the river, the presence of the crop at a very low altitude from the river have been selected. Based on rainfall data the model has run on 6-h rainfall data the model has been run and information generated on water discharge, discharge time and volume of discharge of selected points

In Yumthang, the direct flow of the pick discharge time is $6769 \mathrm{~m}^{3} / \mathrm{s}$ and the total amount of water pass in this session is $1,281,889.7\left(1000 \mathrm{~m}^{3}\right)$. If this amount of water pass through that flow of the narrow channel, then only a few part of this area are flooded. In Lachung, the direct current of the channel at the pick discharge time is $231.41 \mathrm{~m}^{3} / \mathrm{s}$ and discharge volume is $32,699.5\left(1000 \mathrm{~m}^{3}\right)$. If this amount of volume of flow and discharge occur in this channel, then no flood happened in this area. Due to the wide channel of the river water can flow smoothly without causing a flood.

The result shows in Chungthang area; a junction point of two tributaries of the Teesta River, the flow of pick discharge time is $19,628 \mathrm{~m}^{3} / \mathrm{s}$ and water discharge volume are $4,469,965.2\left(1000 \mathrm{~m}^{3}\right)$. Cause of this, an enormous amount of water volume travels through this part of the river. Though the river channel is extensive at the junction point, it can hold much of water. Therefore, no flood occurred at the junction point. However, the lower parts of this point where the river channel become a narrow agent, the water height rises.

Singtam located in the lower part of the watershed. It is located at the elevation of 321 meters above the sea level. In Singtam the direct flow of the pack discharge time is $30,965 \mathrm{~m}^{3} / \mathrm{s}$ and water discharge volume is $7,180,693.8 \mathrm{~m}^{3}$. If this much of water passes through then, the narrow river channel cannot hold this water. Therefore, overflow occurs and surrounding part of the river, which are present at a lower height, is flooded.

Rongpo located at an elevation of $292 \mathrm{~m}$ above the MSL. Though it situated at a lower elevation and the lower part of the basin, an enormous amount of water accumulates here. Therefore, the flash flood may occur here. According to Fig. 8 in Rongpo, the direct flow at the peak discharge time is $35,595.2 \mathrm{~m}^{3} / \mathrm{s}$ and water volume at the channel is $7,968,635.6 \mathrm{~m}^{3}$. If this amount of water passes through the channel of this part then is cannot hold the channel and flood occurs.

Jourthang is situated at an elevation of $278 \mathrm{~m}$. This area is at the left part of the lower Teesta basin. The catchment of this point is small, so the water pass through this channel is also low in volume. In this area, Fig. 8 the flow amount of the peak discharge time is $13,419.1 \mathrm{~m}^{3} / \mathrm{s}$ and the volume of water that passes at this time is $2,705,446.8 \mathrm{~m}^{3}$. Here based on this amount of water, flood analysis was done and found that the settlements of Jourthang area are not under threat, but some agricultural land that is present at the low level will be affected by this amount of water.
Table 2 Total rain fall amount of Teesta watershed

\begin{tabular}{lcrlrl}
\hline Date & \multicolumn{2}{l}{ Rain fall $(\mathrm{mm})$} & \multirow{2}{*}{ Total rain fall (mm) } \\
\cline { 2 - 4 } & $0: 00 \mathrm{~h}$ & $6: 00 \mathrm{~h}$ & $12: 00 \mathrm{~h}$ & $18: 00 \mathrm{~h}$ & \\
\hline 2-Oct-1968 & 80 & 120 & 140 & 60 & 400 \\
3-Oct-1968 & 70 & 90 & 140 & 120 & 420 \\
4-Oct-1968 & 130 & 90 & 110 & 130 & 460 \\
5-Oct-1968 & 110 & 190 & 150 & 49 & 499 \\
\hline
\end{tabular}




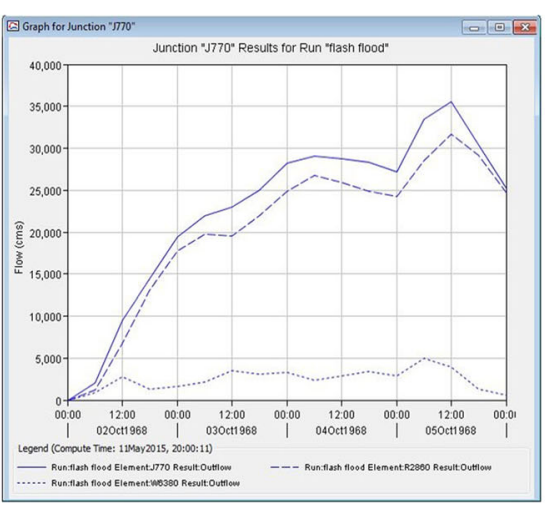

Rangpo

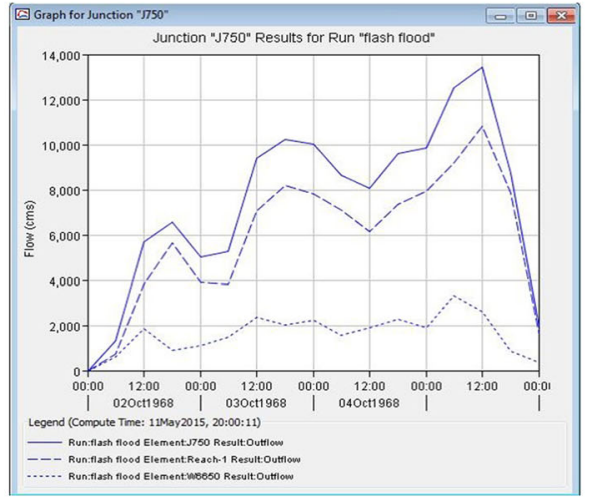

Jourthang

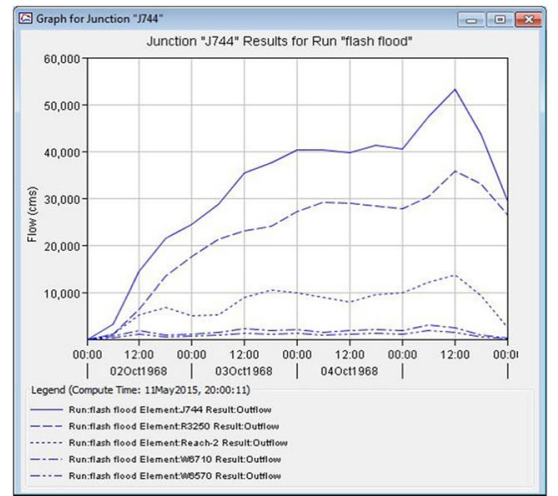

Melli

Fig. 8 Hydrograph generation for selected river junction points of the study area (Sikkim watershed)

Melli is another junction point that situated at the lower part of the river basin. It is located at an elevation of $243 \mathrm{~m}$ above the MSL. This point is the lowest point of the analysis. Here all the water accumulates in the channel, so the water volume and direct flows are much more than the other points. In Fig. 8 the direct flow at the peak discharge time is $53,222.4 \mathrm{~m}^{3} / \mathrm{s}$ and the discharge time of water volume is $11,363,998.1 \mathrm{~m}^{3} / \mathrm{s}$. Here the river channel is narrow therefore; the water can rise covering a considerable part of the locality.

\section{Conclusion}

In this entire study, the Teesta basin has been analyzed, and a simulation model of it has been created. Based on the past rainfall event of this area the Flash flood simulation model has been run, and some information has been generated on water discharge, peak discharge time and volume of discharge of selected points, which are very helpful for flash flood analysis. In the real world situation based on any substantial rainfall, the peak discharge time and its volume can be predicted, and the total area of inundation can be assessed. Therefore, the people of this region could be alarmed before the water hit the area. In this process, the total loss of life and property can be minimized. This research is equipped with highly scientific and contemporary methodologies with reliable satellite data products. Therefore, this is a unique venture, first of its kind in this region showing the way of flood prediction based on advanced technological know-how. When the local authority will make use of the model, the downtrodden aborigines of the region will get the maximum benefit. This model also can be applied in other flash flood prone area of the world for early warning and rescue operation.

\section{References}

Borga M, Anagnostou EN, Blöschl G, Creutin J-D (2011) Flash flood forecasting, warning and risk management: the HYDRATE project. Environ Sci Policy 14(7):834-844

Borga M, Stoffel M, Marchi L, Marra F, Jakob M (2014) Hydrogeomorphic response to extreme rainfall in headwater systems: flash floods anddebrish flows. J Hydrol 518:194-205

Das S, Kar NS, Bandyopadhyay S (2015) Glacial lake outburst flood at Kedarnath, Indian Himalaya: a study using digital elevation models and satellite images. Nat Hazards. doi:10.1007/s11069015-1629-6

Garambois PA, Larnier K, Roux H, Labat D, Dartus D (2014) Analysis of flash flood-triggering rainfall for a process-oriented hydrological model. Atmos Res 137:14-24

Koutroulis AG, Tsanis IK (2010) A method for estimating flash flood peak discharge in a poorly gauged basin: case study for the 13-14 January 1994 flood Giofiros basin, Crete, Greece. J Hydrol 385:150-164

Marchi L, Borga M, Preciso E, Gaume E (2010) Characterisation of selected extreme flash floods in Europe and implications for flood risk Management. J Hydrol 394(1-2):118-133

Nikolopoulos EI, Anagnostou EN, Borga M, Vivoni ER, Papadopoulos A (2011) Sensitivity of a mountain basin flash flood to initial wetness condition and rainfall variability. J Hydrol 402:165-178

Rao KHV, Rao VV, Dadhwal VK, Diwakar PG (2014) Kedarnath flash floods: a hydrological and hydraulic simulation study. Curr Sci 106(4):598-603

Sangati M, Borga M, Rabuffetti D, Bechini R (2009) Influence of rainfall and soil properties spatial aggregation on extreme flash flood response modeling: an evaluation based on the Seisariver basin, North Western Italy. Adv Water Resour 32(7):1090-1106

Soulis KX, Valiantzas JD (2012) SCS-CN parameter determination using rainfall-runoff data in heterogeneous watersheds-the twoCN system approach. Hydrol Earth Syst Sci 16:1001-1015

US Army Corps of Engineers Hydrologic Engineering Centre (USACE) (2008) Hydrologic modeling system: technical reference manual. USACE-HEC, Davis

Wiejaczka L, Bucała A, Sarkar S (2014) Human role in shaping the hydromorphology of Himalayan rivers: study of the Tista River in Darjeeling Himalaya. Curr Sci 106(5):717-724

Wu S-J, Hsu C-T, Lien H-C, Chang C-H (2015) Modeling the effect of uncertainties in rainfall characteristics on flash flood warning based on rainfall thresholds. Nat Hazards 75:1677-1711. doi:10. 1007/s11069-014-1390-2 
Zenon F, Borga M, Zoccatelli D, Marchi L, Gaume E, Bonnifait L, Delrieu G (2010) Hydrological analysis of a flash flood across a climatic and Geologic gradient: the September 18, 2007 event in Western Slovenia. J Hydrol 394:182-197
Zoccatelli D, Borga M, Zanon F, Antonescu B, Stancalie G (2010) Which rainfall Spatial information for flash flood response modeling? A numerical investigation based on data from the Carpathian range. Romania. J Hydrol 394(1-2):148-161 